\title{
Bibliometric analysis of recent research on multidrug and antibiotics resistance $(2017-2018)$
}

\author{
David Gómez-Ríos ${ }^{1}$, Howard Ramírez-Malule ${ }^{2 *}$ \\ ${ }^{1}$ Grupo de Investigación en Simulación, Diseño, Control y Optimización de Procesos (SIDCOP), Facultad de Ingeniería, Universidad de Antioquia UdeA, \\ Calle 67 No. 53-108, Medellín 050010, Colombia. \\ ${ }^{2}$ Escuela de Ingeniería Química, Universidad del Valle, A.A. 25360 Cali, Colombia.
}

\section{ARTICLE INFO \\ Received on: 27/01/2019 \\ Accepted on: 09/03/2019 \\ Available online: 08/05/2019}

\section{Key words:}

Antibiotics resistance, multidrug resistance,

bibliometric analysis.

\begin{abstract}
Antibiotic resistance is considered, nowadays, as a severe public health problem. In February 2017, the World Health Organization (WHO) reported the global priority list of antibiotic-resistant bacteria as a guide for further research on the field. This contribution presents a bibliometric overview of global research on multidrug and antibiotics resistance. Research articles indexed between 2017 and 2018 on the Scopus database were filtered according to a systematic search strategy and a total of 2,362 records were retrieved. A significative number of studies were found to be focused on four pathogenic bacteria: Escherichia coli, Pseudomonas aeruginosa, Acinetobacter baumannii, and Klebsiella pneumoniae, which were also included in the critical priority level according to the WHO. The results of this study indicate that the United States, China, and India were the most productive countries regarding the number of publications. Furthermore, publications from the United States, Germany, and the United Kingdom had the highest impact based on the ratio of the number of citations and the number of publications. Nevertheless, when productivity was stratified by the number of publications and the number of citations based on the gross domestic product, Iran ranked first. This bibliometric approach showed that most of multidrug- and antibiotics-resistance studies focused on the so-called critical bacteria according to the WHO but less on those bacteria catalogued as high and medium priority.
\end{abstract}

\section{INTRODUCTION}

Antibiotic is considered as one of the most important discoveries in the history of medicine since they made possible the effective treatment of infectious diseases saving millions of human lives in about seven decades. However, the inappropriate use of commercial antibiotics in humans and agriculture, along with the evolution and spread of mobile genetic resistance elements, has triggered the increase of multidrug resistance (MDR) and extremely drug resistance in the last decades (Banin et al., 2017). In February 2017, the World Health Organization (WHO) published the global priority list of antibiotic-resistant bacteria aiming to guide the research and development efforts of new and effective antibiotic treatments in the next years (World

${ }^{*}$ Corresponding Author

Howard Ramírez-Malule, Escuela de Ingeniería Química, Universidad del Valle, Cali,Colombia.E-mail: howard.ramirez@correounivalle.edu.co
Health Organization, 2017). The report classified 12 bacteria and bacterial families in three categories of priority: (i) critical, (ii) high, and (iii) medium. The classification of those bacterial groups and their specific resistance are presented in Table 1 (World Health Organization, 2017).

The pathogenicity level of those priority bacteria and their resistance to most of the recent antibiotic treatments suggest that an effective scientific collaboration between different disciplines in several fields is necessary to face this resistance phenomenon. In this regard, bibliometric analysis constitutes a holistic framework for monitoring the research efforts on a particular field and to identify the characteristics of those studies. Despite the extensive research on the disease and antibiotic area (Liao et al., 2018; Ramirez-Malule, 2018; Soosaraei et al., 2018; Sweileh et al., 2016), a lack of bibliometric studies regarding multidrug and antibiotics resistance was identified. This contribution presents a bibliometric analysis of the most recent scientific contributions in the multidrug and antibiotics resistance fields in the period between 2017 and 2018. 
Table 1. Global priority list of antibiotic-resistant bacteria reported by the World Health Organization [adapted from World Health Organization (2017)].

\begin{tabular}{|c|c|c|c|c|c|}
\hline \multicolumn{6}{|c|}{ Priority } \\
\hline \multicolumn{2}{|c|}{ Critical* } & \multicolumn{2}{|c|}{ High } & \multicolumn{2}{|c|}{ Medium } \\
\hline Strain & Note & Strain & Note & Strain & Note \\
\hline Acinetobacter baumannii & Carbapenem-resistant & Enterococcus faecium & $\begin{array}{l}\text { Vancomycin-resistant. } \\
\text { Methicillin-resistant, } \\
\text { Vancomycin intermediate } \\
\text { and resistant. }\end{array}$ & $\begin{array}{l}\text { Streptococcus } \\
\text { pneumoniae }\end{array}$ & Penicillin-non-susceptible \\
\hline Pseudomonas aeruginosa & Carbapenem-resistant & $\begin{array}{l}\text { Helicobacter pylori } \\
\text { Campylobacter }\end{array}$ & $\begin{array}{l}\text { Clarithromycin-resistant. } \\
\text { Fluoroquinolone-resistant. }\end{array}$ & $\begin{array}{l}\text { Haemophilus } \\
\text { influenza }\end{array}$ & Ampicillin-resistant \\
\hline Enterobacteriaceae** & $\begin{array}{l}\text { Carbapenem-resistant, } \\
\text { third generation } \\
\text { cephalosporin-resistant }\end{array}$ & $\begin{array}{l}\text { Salmonella spp. } \\
\text { Neisseria gonorrhoeae }\end{array}$ & $\begin{array}{l}\text { Fluoroquinolone-resistant. } \\
\text { Third generation } \\
\text { cephalosporin-resistant, } \\
\text { fluoroquinolone-resistant. }\end{array}$ & Shigella spp. & Fluoroquinolone-resistant \\
\hline
\end{tabular}

* Mycobacteria (including Mycobacterium tuberculosis, the cause of human tuberculosis) were not included in the study carried out by WHO. **Enterobacteriaceae include: Klebsiella pneumonia, Escherichia coli, Enterobacter spp., Serratia spp., Proteus spp., Providencia spp., and Morganella spp. (WHO).

Table 2. Top-10 leading authors of multidrug- and antibiotics-resistance studies between 2017 and 2018 .

\begin{tabular}{|c|c|c|c|}
\hline Rank & Authors & Affiliation & No. of publications \\
\hline 1 & Oliver A. & $\begin{array}{l}\text { Hospital Universitario Son Espases, Instituto de Investigación Sanitaria } \\
\text { Illes Balears (IdISBa), Palma, Spain }\end{array}$ & 13 \\
\hline 2 & Flamm RK. & JMI Laboratories Incorporated, North Liberty, United States & 12 \\
\hline 3 & Li J. & Monash University, Department of Microbiology, Melbourne, Australia & 12 \\
\hline 4 & Bonomo RA. & $\begin{array}{l}\text { CASE School of Medicine, Department of Medicine, Cleveland, United } \\
\text { States. }\end{array}$ & 11 \\
\hline 5 & Schwarz S. & $\begin{array}{l}\text { Freie Universitat Berlin, Department of Veterinary Medicine, Berlin, } \\
\text { Germany }\end{array}$ & 11 \\
\hline 6 & $\mathrm{Xu} \mathrm{X}$. & $\begin{array}{l}\text { Shanghai Municipal Center for Disease Control and Prevention, } \\
\text { Department of Microbiology, Shanghai, China }\end{array}$ & 11 \\
\hline 7 & Castanheira M. & JMI Laboratories Incorporated, North Liberty, United States & 10 \\
\hline 8 & Kreiswirth BN & Rutgers New Jersey Medical School, Newark, United States & 10 \\
\hline 9 & Sader HS. & JMI Laboratories Incorporated, North Liberty, United States & 9 \\
\hline 10 & Torres C. & Universidad de La Rioja, Logrono, Spain & 9 \\
\hline
\end{tabular}

\section{METHODS}

For this study, data search and collection were performed from Scopus database. The systematic search strategy included the terms in the title of the article, abstract, and keywords. Additionally, the "document type" was limited only to articles. Thus, the resulting search was as follows:

- [TITLE-ABS-KEY ("multidrug resistance") AND TITLEABS-KEY ("antibiotics resistance")] AND [LIMIT-TO (PUBYEAR, 2018) OR LIMIT-TO (PUBYEAR, 2017)] AND [LIMIT-TO (DOCTYPE, “ar”)].

- Timespan: 2017-2018.

The information retrieved from the Scopus database included: (i) citation information, (ii) bibliographical information, (iii) abstract and keywords, and (iv) other information. The software VOS viewer 1.6.10 was used for visualization and data analysis (van Eck and Waltman, 2010).

\section{RESULTS AND DISCUSSION}

A total of 2,362 documents were found in the Scopus database as published in the years 2017 and 2018. Table 2 shows the most relevant authors, their affiliation, and number of publications that contributed substantially to research on the multidrug and antibiotics resistance fields. The obtained information provides insights about the main researchers and leading institutions in the area, which could be also useful for the identification of collaboration opportunities and funding.

Figure 1 shows the areas of knowledge related to multidrug- and antibiotics-resistance studies. In this case, medicine contributed $38.8 \%$ of the indexed documents, followed by immunology and microbiology and, pharmacology, toxicology and pharmaceutics with $20.5 \%$ and $11.9 \%$, respectively. As expected, medicine was ranked as first on this list since multidrug and antibiotics resistance is directly linked to negative consequences on human health and the increase of morbidity rates (Magira et al., 2018). On the other hand, veterinary also appeared in the top-10 fields since some of those resistant bacteria affect animal health as well (e.g., dogs, cats, horses, camels, among others) (Saputra et al. 2017; Sharma et al. 2017; Videla et al. 2018).

The leading countries in studies related to multidrug and antibiotics resistance were United States and China, which contributed with 474 and 332, respectively. The top-10 leading countries based on the number of publications related to multidrug and antibiotics resistance are shown in Table 3. 
Nevertheless, when the ratio between the number of citations and publications was considered as an indicator of the impact of the research, a redistribution of the top-10 leading countries was observed. In this regard, the United States was the country with the highest impact in the field, followed by Germany and the United Kingdom. This information is coincident with the most productive authors and the countries where their institutes are located (Tables 2 and 3). When productivity was stratified by gross domestic product (GDP), Iran ranked first followed by Spain and India (Table 3) leaving the United States, China, and Germany in the last places. From a different standpoint, if productivity is stratified by calculating the average of the number of citations by GDP, the leading countries were Iran, Spain, and Australia. Interestingly, Iran was the leading country in number of publications - and also number of citations - based on the GDP but had the last place when the ratio of the number of citations and the number of publications was used as an indicator

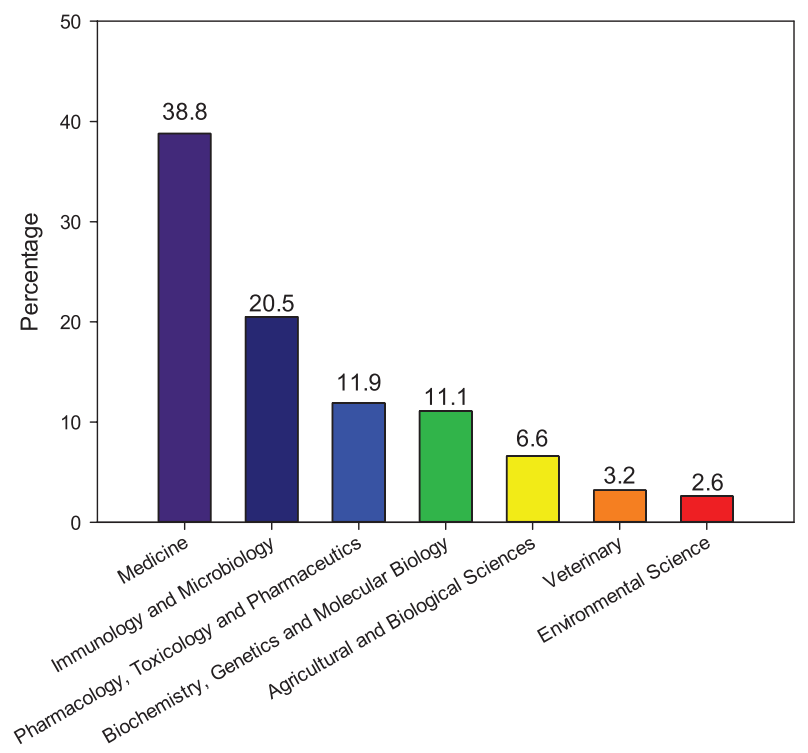

Figure 1. Contributions in multidrug and antibiotics resistance per area of knowledge between 2017 and 2018. Other areas contributed 5.3\%. of the productivity. These results evidence an efficient use of the resources dedicated to research and development of this field in those countries with lower income when compared with the middle-high income countries.

Figure 2 shows the research-topic network of publications regarding multidrug and antibiotics resistance in 2017 and 2018. Notice that five and six clusters were observed for the years 2017 and 2018, respectively. Additionally, the ranking of keywords and their occurrences are presented in Table 4. Interestingly, the top-10 keywords in 2017 and 2018 were the same but in different order.

Antibiotic resistance, MDR, and antimicrobial resistance were the biggest nodes in the network, as expected. Furthermore, a significative number of studies were focused on four pathogenic bacteria: Escherichia coli, Pseudomonas aeruginosa, Acinetobacter baumannii, and Klebsiella pneumoniae, which are included in the critical priority level according to the WHO (Table 1). This information suggests that important scientific efforts have been dedicated, in the last 2 years, to the study of multidrug and antibiotics resistance in those bacteria (Bassetti et al., 2018; Biswas et al., 2018; Costa et al., 2018; Nazari Alam et al., 2018). Although most of the bacteria considered in the critical priority level (Table 1) has received attention, considerably less importance has been given to those of high and medium priority level. Therefore, it is necessary to intensify the research focused on those bacterial groups that also represent a high risk for human and animal health.

Institutions have an important role not only in the research but also in the formulation of disease control policies and strategies. As shown in Figure 3, the leading institutions included universities, research centers, and government entities.

In total, 4,421 institutions were involved in 1,309 publications in the year 2017 and 3,846 participated in 1,053 contributions in 2018. These numbers lead to a ratio of 3.4 and 3.6 institutions per article during the years 2017 and 2018, respectively. In this regard, and for the case of the year 2017, only 41 institutions reached the threshold of three published articles but only four of these institutions were interconnected. When the threshold was augmented to five articles, only three institutions appeared and all of them were disconnected. A similar behavior was observed for the year 2018. Therefore, it is clear that stronger collaboration efforts are required to deal with this global health problem.

Table 3. Top-10 leading countries of multidrug- and antibiotics-resistance studies between 2017 and 2018 .

\begin{tabular}{|c|c|c|c|c|c|c|c|}
\hline Rank & Country & No. of publications & No. of citations & $\begin{array}{l}\text { GDP* (in trillions } \\
\text { of U.S. dollars) }\end{array}$ & $\begin{array}{c}\text { No. of citations/No. of } \\
\text { publications }\end{array}$ & No. of publications/GDP & No. of citations/GDP \\
\hline 1 & United States & 474 & 2,412 & 19.4 & $5.1(1)$ & $24.4(10)$ & $124.3(8)$ \\
\hline 2 & China & 332 & 1,036 & 12.2 & $3.1(6)$ & $27.2(9)$ & $84.9(10)$ \\
\hline 3 & India & 188 & 426 & 2.6 & $2.3(9)$ & $72.3(3)$ & $163.8(6)$ \\
\hline 4 & United Kingdom & 149 & 679 & 2.6 & $4.6(3)$ & $57.3(5)$ & $261.2(4)$ \\
\hline 5 & Spain & 134 & 418 & 1.3 & $3.1(7)$ & $103.1(2)$ & $321.5(2)$ \\
\hline 6 & Iran & 128 & 269 & 0.4 & $2.1(10)$ & $320.0(1)$ & $672.5(1)$ \\
\hline 7 & Germany & 118 & 591 & 3.7 & $5.0(2)$ & $31.9(8)$ & $159.7(7)$ \\
\hline 8 & France & 114 & 505 & 2.6 & $4.4(4)$ & $43.8(7)$ & $194.2(5)$ \\
\hline 9 & Brazil & 93 & 230 & 2.1 & $2.5(8)$ & $44.3(6)$ & $109.5(9)$ \\
\hline 10 & Australia & 87 & 349 & 1.3 & $4.0(5)$ & $66.9(4)$ & $268.5(3)$ \\
\hline
\end{tabular}

*Gross domestic product (GDP), 2017. Source: The World Bank (2018). 


\section{fos vosiewer}

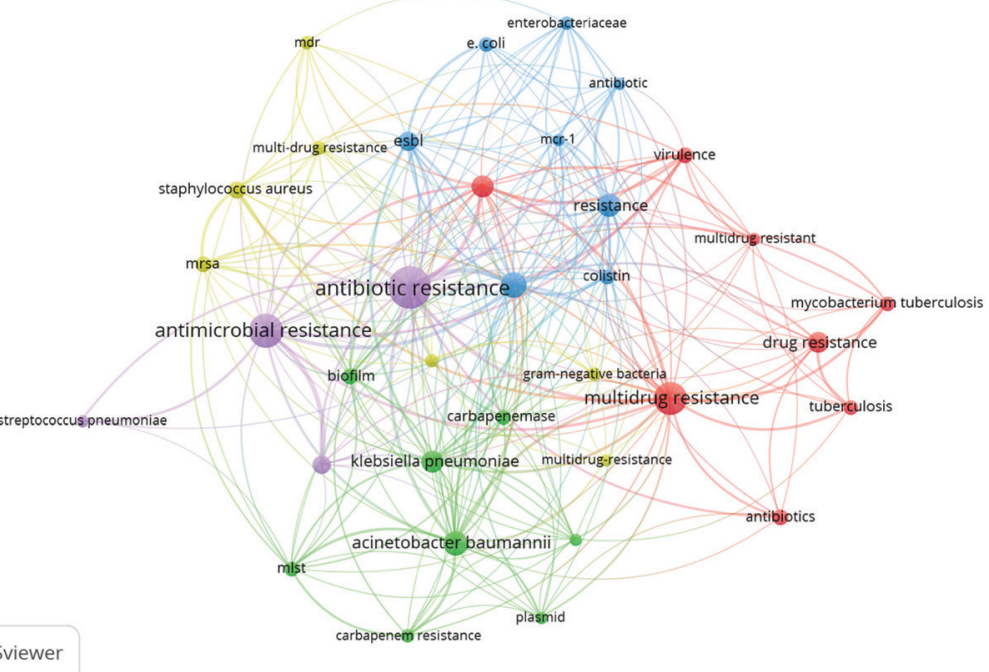

\section{B Vosviewer}

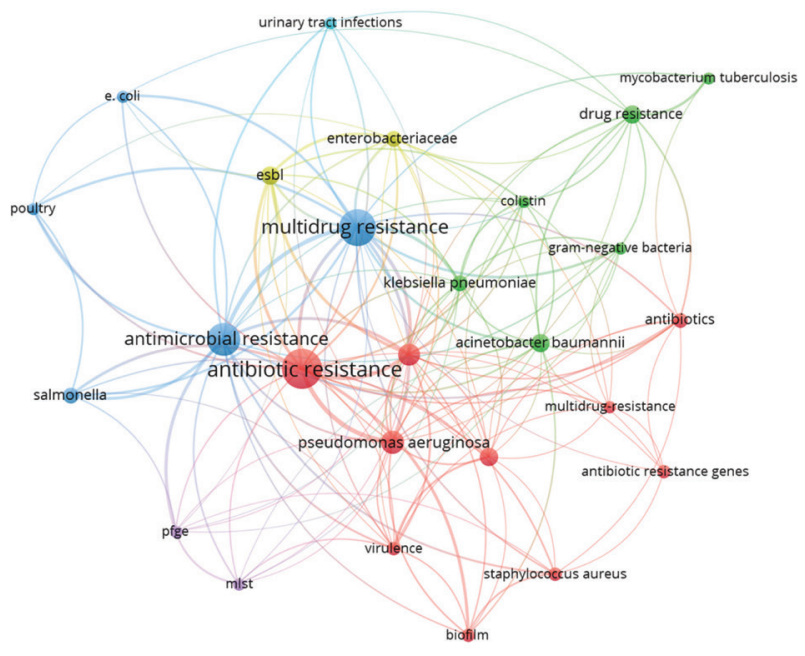

Figure 2. Research-topic network visualization of publications related to multidrug and antibiotics resistance. (a) Year 2017. (b) Year 2018. Note: the minimum number of occurrences of a keyword is 15.

Table 4. Top-10 keywords of multidrug- and antibiotics-resistance studies in the period of 2017-2018.

\begin{tabular}{clclc}
\hline \multicolumn{2}{c}{$\mathbf{2 0 1 7}$} & \multicolumn{2}{c}{$\mathbf{2 0 1 8}$} \\
\hline Rank & Keywords & Occurrences & Keywords & Occurrences \\
\hline 1 & Antibiotic resistance & 181 & Antibiotic resistance & 163 \\
2 & Antimicrobial resistance & 118 & MDR & 139 \\
3 & MDR & 106 & Antimicrobial resistance & 110 \\
4 & Escherichia coli & 67 & Pseudomonas aeruginosa & 55 \\
5 & Acinetobacter baumannii & 58 & Escherichia coli & 52 \\
6 & Resistance & 54 & Drug resistance & 37 \\
7 & Pseudomonas aeruginosa & 52 & Esbl & 37 \\
8 & Klebsiella pneumoniae & 50 & Acinetobacter baumannii & 36 \\
9 & Drug resistance & 42 & Resistance & 36 \\
10 & Esbl & 39 & Klebsiella pneumoniae & 27 \\
\hline
\end{tabular}




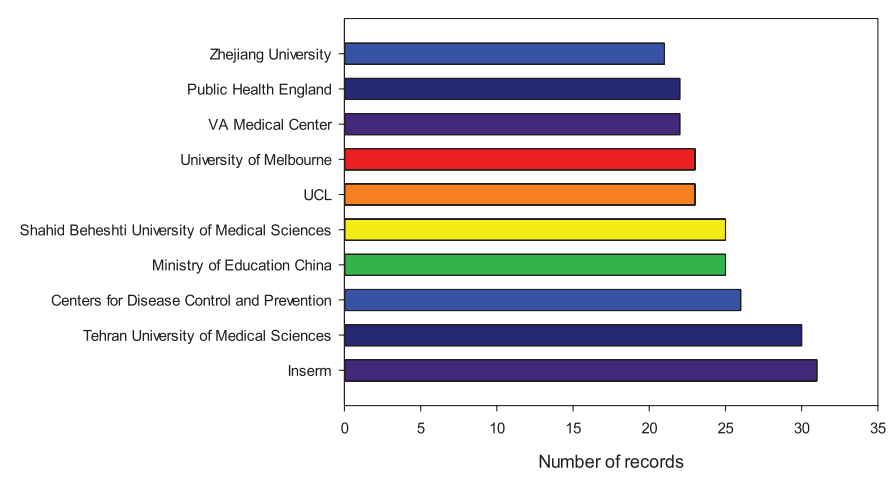

Figure 3. Top-10 leading institutions in research on multidrug and antibiotics resistance in the period between 2017 and 2018.

\section{FUTURE PERSPECTIVES}

Multidrug and antibiotics resistance are global concern issues (World Health Organization, 2017). New drug combinations, novel antimicrobial compounds, in addition to better understanding of the biological causes of resistance and mechanisms of dispersion, undoubtedly will help to deal with the antibiotics-resistance problem (Frieri et al., 2017; Piddock, 2017). The creation of further collaboration networks, including different countries, universities, research centers, and government entities is needed to confront and overcome the challenges of the multidrug and antibiotics resistance.

\section{CONCLUSION}

A total of 2,362 articles were published between 2017 and 2018 in the field of multidrug and antibiotics resistance. The research efforts were mainly focused on the critical bacteria according to the WHO priority list, in contrast with the low research activity dealing with high and medium priority bacteria. In terms of the areas: (i) Medicine, (ii) immunology and microbiology, and (iii) pharmacology, toxicology, and pharmaceutics concentrated the majority of multidrug- and antibiotics-resistance studies. The United States, China, and India were the top-leading countries according to the number of publications. Nevertheless, the United States, Germany, and the United Kingdom had the highest impact of their publications based on the ratio of number of citations and number of publications. Iran was the leading country related to number of publications - and also to number of citations-based on the GDP. Finally, a strengthening of scientific collaboration is required for dealing with this global health problem and ensures successful implementation of new antibacterial treatments.

\section{FUNDING}

This research was funded by Universidad del Valle (grant number CI 131).

\section{CONFLICT OF INTEREST}

Authors declare that there are no conflict of interest.

\section{REFERENCES}

Banin E, Hughes D, Kuipers OP. Bacterial pathogens, antibiotics and antibiotic resistance. FEMS Microbiol Rev, 2017; 41:450-2.
Bassetti M, Vena A, Russo A, Croxatto A, Calandra T, Guery B. Rational approach in the management of P.aeruginosa infections. Curr Opin Infect Dis, 2018; 31:578-86.

Biswas D, Tiwari M, Tiwari V. Comparative mechanism based study on disinfectants against multidrug-resistant Acinetobacter baumannii. J Cell Biochem, 2018; 119:10314-26.

Costa AR, Monteiro R, Azeredo J. Genomic analysis of Acinetobacter baumannii prophages reveals remarkable diversity and suggests profound impact on bacterial virulence and fitness. Sci Rep, 2018; 15346:1-11.

Frieri M, Kumar K, Boutin A. Antibiotic resistance. J Infect Public Health, 2017; 10:369-78

Liao H, Tang M, Luo L, Li C, Chiclana F, Zeng XJ. A bibliometric analysis and visualization of medical big data research. Sustainability, 2018; 166:1-18.

Magira EE, Islam S, Niederman MS. Multi-drug resistant organism infections in a medical ICU: association to clinical features and impact upon outcome. Med Intensiva, 2018; 42:225-34.

Nazari Alam A, Sarvari J, Motamedifar M, Khoshkharam H, Yousefi M, Moniri R, Bazargani A. The occurrence of blaTEM, blaSHV and blaOXA genotypes in Extended-Spectrum $\beta$-Lactamase (ESBL)-producing Pseudomonas aeruginosa strains in Southwest of Iran. Gene Rep, 2018; $13: 19-23$

Piddock LJV. Understanding drug resistance will improve the treatment of bacterial infections. Nat Rev Microbiol, 2017; 15:639-40.

Ramirez-Malule H. Bibliometric analysis of global research on clavulanic acid. Antibiotics, 2018; 102:1-14.

Saputra S, Jordan D, Mitchell T, Wong HS, Abraham RJ, Kidsley A, Turnidge J, Trott DJ, Abraham S. Antimicrobial resistance in clinical Escherichia coli isolated from companion animals in Australia. Vet Microbiol, 2017; 211:43-50.

Sharma SK, Patel K, Maherchandani S, Shring BN. ESBL detection and comparison of antibiotics resistance pattern of Klebsiella Pneumoniae isolated from healthy and acute respiratory tract infected camels. Adv Anim Vet Sci, 2017; 5:83-91.

Soosaraei M, Khasseh AA, Fakhar M, Hezarjaribi HZ. A decade bibliometric analysis of global research on leishmaniasis in Web of Science database. Ann Med Surg, 2018; 26:30-7.

Sweileh WM, Shraim NY, Al-Jabi SW, Sawalha AF, AbuTaha AS, Zyoud SH. Bibliometric analysis of global scientific research on carbapenem resistance (1986-2015). Ann Clin Microbiol Antimicrob, 2016; 56:1-11.

The World Bank. World development indicators. [Online] 2018. Available via https://datacatalog.worldbank.org/dataset/gdp-ranking (Accessed 4 December 2018).

van Eck NJ, Waltman L. Software survey: VOSviewer, a computer program for bibliometric mapping. Scientometrics, 2010; 84:523-38.

Videla R, Solyman SM, Brahmbhatt A, Sadeghi L, Bemis DA, Kania SA. Clonal complexes and antimicrobial susceptibility profiles of Staphylococcus pseudintermedius isolates from dogs in the united states. Microb Drug Resist, 2018; 24:83-8.

World Health Organization. Global priority list of antibioticresistant bacteria to guide research, discovery, and development of new antibiotics. [Online] 2017. Available via http://www.who.int/medicines/ publications/global-priority-list-antibiotic-resistant-bacteria/en/ (Accessed 11 May 2018).

How to cite this article:

Gómez-Ríos D, Ramírez-Malule H. Bibliometric analysis of recent research on multidrug and antibiotics resistance (2017-2018). J Appl Pharm Sci, 2019; 9(05):112-116. 